\title{
STABILIZATION OF THE GENERALIZED RAO-NAKRA BEAM BY PARTIAL VISCOUS DAMPING
}

\author{
Mohammad $\mathrm{AKIL}^{1}$ and Zhuangyi Liu ${ }^{2}$ \\ ${ }^{1}$ Université Polytechnique Hauts-de-France \\ ${ }^{2}$ University of Minnesota Duluth
}

December 21, 2021

\begin{abstract}
In this paper, we consider the stabilization of the generalized Rao-Nakra beam equation, which consists of four wave equations for the longitudinal displacements and the shear angle of the top and bottom layers and one Euler-Bernoulli beam equation for the transversal displacement. Dissipative mechanism are provided through viscous damping for two displacements. The location of the viscous damping are divided into two groups, characterized by whether both of the top and bottom layers are directly damped or otherwise. Each group consists of three cases. We obtain the necessary and sufficient conditions for the cases in group two to be strongly stable. Furthermore, polynomial stability of certain orders are proved. The cases in group one are left for future study.
\end{abstract}

\section{Hosted file}

LIU-AKIL-2021.pdf available at https://authorea.com/users/452101/articles/550244stabilization-of-the-generalized-rao-nakra-beam-by-partial-viscous-damping

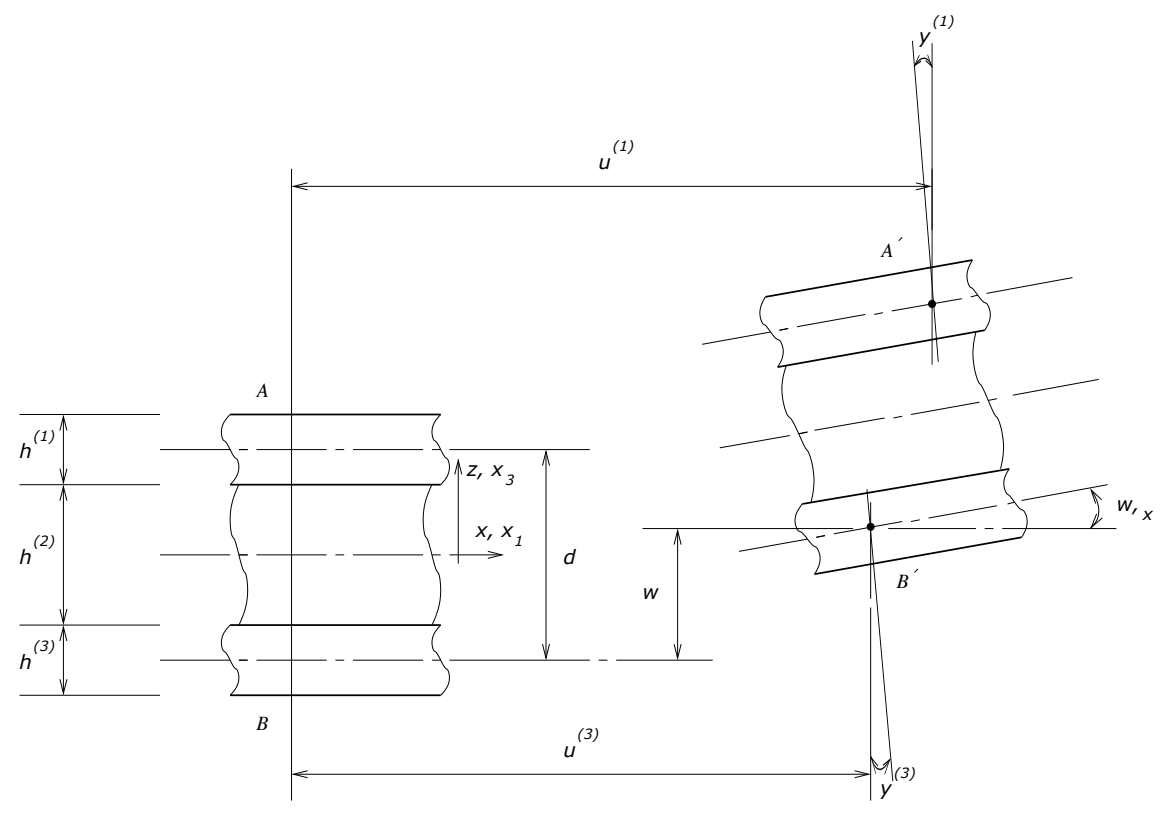

